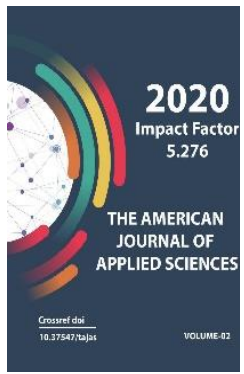

\title{
A Study Of The Process Of The Final Distillation Of Cottonseed Oil On The Computer Model
}

\author{
F.Yu.Khabibov \\ Bukhara Engineering Technological Institute, Bukhara, Uzbekistan
}

\begin{abstract}
Journal Website: http://usajournalshub.c om/index,php/tajas

Copyright: Original content from this work may be used under the terms of the creative commons attributes 4.0 licence.
\end{abstract}

\section{ABSTRACT}

The development of computer technology, technology and its software provides opportunities for their wide use in analytical studies of chemical processes. The final distillation of cottonseed oil refers to the processes of distillation by means of sharp steam, in which the mass transfer occurs between the liquid and vapor phases. The study of technological processes on the computer model is based on the logic of formation contributing to the definition of the main influencing factors of the object under study. To compile a computer model of the technological process, mathematical descriptions of each process and for the process are developed. The generalization to the General model obtained a complete mathematical model of the process of the final miccella distillation of cottonseed oil. An algorithm for the study of a computer model that will flow on the new design of the three-stage distiller. The computer model is developed for a three-stage device, in which the output values of the first stage will be input for the second stage, etc according to the obtained graphs, as a result of the study of the computer model, it is clear that in the new design of the device the mass transfer process between the phases is more intense, and there is a possibility to study the process for different technological modes of its introduction.

\section{KEYWORDS}

Simulation, initial conditions, Dalton's law, volatile component, hydrodynamic structure, liquid phase. 


\section{INTRODUCTION}

Computer simulation is one of effective methods of studying processes. Often, computer models are easier to explore, they allow for computational experiments, the real production of which is difficult or may give unpredictable results. The consistency of computer models allows to identify the main factors determining the properties of the objects under study, to investigate the response of the physical system to changes of its parameters and initial conditions. Many scientists studied the processes by analytical methods [1].

Our research of the process of mass transfer during final distillation of the micelle cottonseed oil based system analysis.

$$
P_{(\text {general })}=P_{(\text {petrol })}+P_{(\text {wat.steam. })}+P_{(\text {oil })}
$$

When the system analysis of the mathematical descriptions of the process under study starts from the lower level of the hierarchy, as subprocess, the partial pressure of the component.

\section{METHODS AND MATERIALS}

To determine a stable concentration of light volatiles is necessary to determine the partial pressure of the components. According to Dalton's law, the pressure of the gas mixture $(p)$ is the sum of the partial pressures of its components [2].

Here, $\mathrm{P}_{\text {(petrol) }}, \mathrm{P}_{\text {(wat.steam) }} \mathrm{P}_{\text {(oil) }}$ are the corresponding partial pressure of gasoline, the input of steam and volatile components of oil, $\mathrm{kPa}$.

After some mathematical transformations of the equation will get a mathematical change in the partial pressure of the volatile component in the vapor phase, which can be represented in the following form with the help of computer graphics:

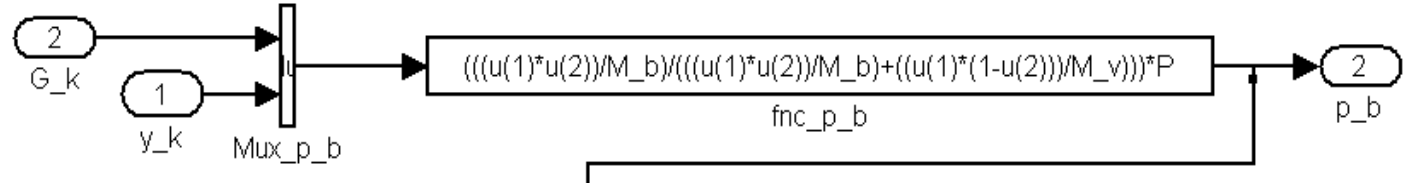

Fig.1. A computer model of the process of change of partial pressures of letuchih substances of miccella in vegetable oil: $u(1)=G, u(2)=y$.

Knowing the partial pressure of the volatile component, it is possible todetermine the equilibrium concentration in the liquid phase. 


$$
x^{*}=\frac{p}{\left(b_{11} t-b_{10}\right)-100}
$$

Then the image in computer graphics, equilibrium concentrations will change so:

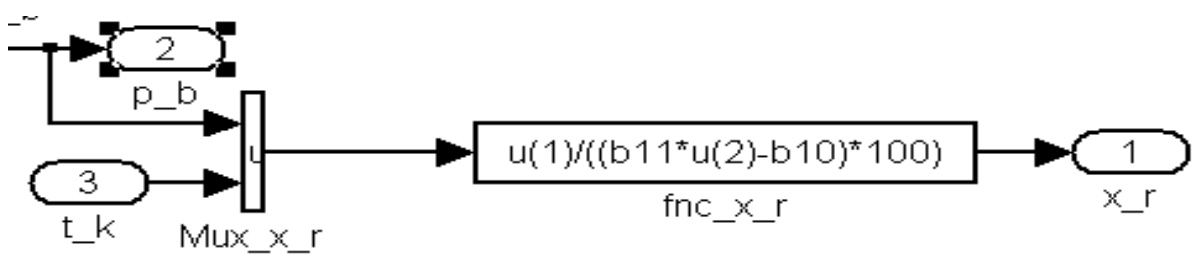

Fig.2. In the classical calculation methods are sometimes used, the saturation level of acute water vapor (an inert gas) distillation of the miccella, it is characterized by koeffitcient:

$$
\phi=\frac{P_{p s t}}{P_{p \cdot p r e s s p a t}}
$$

Here, $\mathrm{P}_{(\mathrm{pet})}$-the practical effect of the partial pressure of vapor extract gasoline miccella, $\mathrm{R}_{(\mathrm{p} \text {.press.pet)- }}$ parzialmente the vapor pressure equilibrium.

The vapor phase can be viewed as an ideal gas. The partial pressure will change in accordance with the number of molecules of each component.

The mathematical expression of the change of the petrol extract in the liquid phase are determined by material equality.

Supplied sharp steam vaporizes the lighter components of the liquid phase in the working zones of the machine.

The hydrodynamic structure of the gas and liquid phases can be taken into account by the model of ideal mixing in the equipment [3]:

$$
\frac{d m_{\text {pat }}}{d \tau}=G_{\text {pet }}-G_{\text {pet amice }}-G_{\text {petwat steam }}
$$

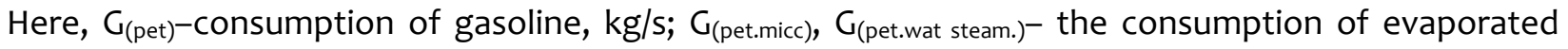
petrol vapor in the vapor phase and offset the petrol extract from the miccella, $\mathrm{kg} / \mathrm{s}$;

The mathematical expression for the temperature change of the liquid phase can be determined by heat balance.

$$
\frac{d Q_{\text {mice }}}{d \tau}=q_{\text {mice }}-q_{\text {oil }}-q_{\text {pet }}-q_{\text {watsteam }}
$$

Here: $\mathrm{q}_{(\text {micc) }}$ - the incoming energy from the miccella, $\mathrm{kJ} / \mathrm{s} ; \mathrm{q}_{(\mathrm{oil})}$ - emerging energy miccella, $\mathrm{kJ} / \mathrm{s} \mathrm{q}_{(\mathrm{pet})}$ is the heat that removes the molecule extract gasoline in the vapor phase, $\mathrm{kJ} / \mathrm{s} \mathrm{q}_{(\mathrm{pet})}$-the heat transfer from vapor phase to liquid phase, $\mathrm{kJ} / \mathrm{s}$. 
From the heat balance equation (5) after mathematical transformations the equations above with formalized mathematical description and computer model characterizing the temperature change of the liquid phase [4]:

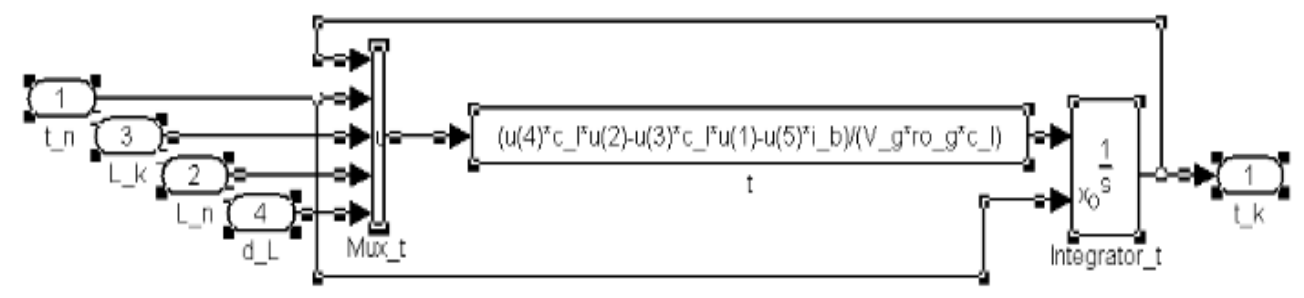

Fig.3. A computer model of the process of temperature change of the liquid phase.

Acute water vapor moves from the miccella in the working area of the machine. Applying the hydrodynamic structure of the phases as perfect mixing in the following expression

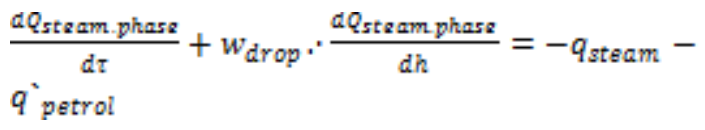

Here, $\mathrm{Q}_{\text {(steam.phase) }}$ - the amount of heat of the steam phase, $\mathrm{kJ} ; \mathrm{w}_{\text {(steam)- }}$ - steam speed, $\mathrm{m} / \mathrm{s}$, consumption of acute water vapor can be taken as a constant flow, $\mathrm{q}_{\text {(steam) }}$ - heat consumption of steam, $\mathrm{kJ}, \mathrm{q}_{\text {(pet)- }}$ heat consumption for heating molecules of extraction gasoline, passing from the liquid phase to the steam, kJ [5].

Studies in the computer model show that the influence of the heat fraction of the gas phase is negligible when using higher power heat sources.

Mass transfer process is the difference in the concentration of the distributed substance in the interacting phases. Consequently, the amount of substances $M$ in the transition from the first phase to the second phase in time is expressed in this way [5]:

$$
\begin{aligned}
& M=K_{y} F(y-y *) \\
& M=K_{x} F(x *-x)
\end{aligned}
$$

Here, $\mathrm{K}_{(\mathrm{y})}$ is the mass transfer coefficient representing the concentration of the gas phase, $\mathrm{K}_{(\mathrm{x})}$ is the mass transfer coefficient representing the concentration of the liquid phase.

The effective force of mass transfer is the difference between the equilibrium and operating concentrations of the components.

Volumetric mass transfer coefficient.

$$
V=F / a,
$$


Here, a- is the specific contact area of the phases, $\mathrm{m}_{2} / \mathrm{m} 3$. With the formula (8) in mind, we obtain:

$$
\begin{aligned}
& M=K_{y} a V(y-y *)=K_{y V} V(y-y *) \\
& M=K_{x} a V(x *-x)=K_{x V} V(x *-x)
\end{aligned}
$$

Here, $\mathrm{K}_{(\mathrm{y})} \mathrm{V}$ and $\mathrm{K}_{(\mathrm{x})} \mathrm{V}$ is the mass transfer coefficient. The mass transfer coefficient can be described using the mass transfer coefficient.

$$
K_{x}=\frac{1}{\left(\frac{1}{g_{x}}+\frac{1}{m \beta_{y}}\right)}
$$

The process of determining the expiration of the volatile component of the liquid phase is primarily a computerized model.

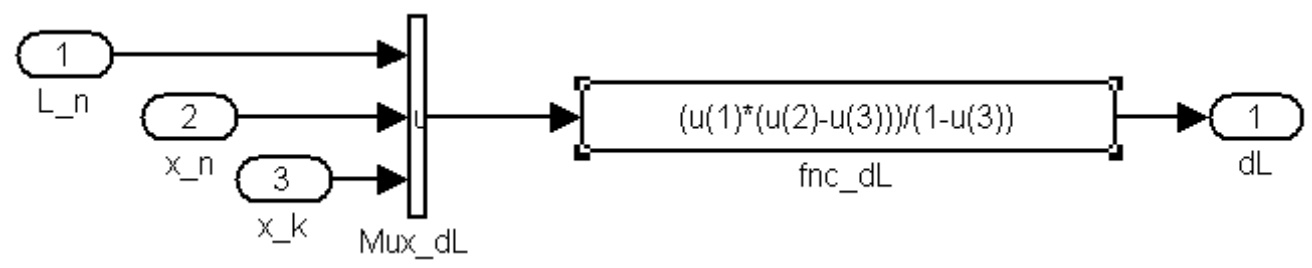

Fig.4. Computer model of the process of transfer of volatile substances flow of vegetable oil miccella from the liquid phase to the gas phase.

The Generalized mathematical model of the process occurring in the working area of the device can be described by the following system of equations: 


$$
\begin{aligned}
& \int \frac{d x}{d \tau}=\frac{L_{\mathrm{i}} X_{\mathrm{i}}-L \cdot x-K_{\mathrm{V}} V_{L}\left(x-x^{*}\right)}{V_{L} p_{L}} \\
& L=L_{i}-\sum \Delta L \\
& \Delta L=\frac{L_{i}\left(X_{i}-x\right)}{1-x} \\
& y=\frac{G_{i}-y_{i}+\Delta L}{G} \\
& G=G_{i}+\sum \Delta L \\
& x^{*}=\frac{p}{\left(b_{11}-t-b_{10}\right)-100} \\
& p=\frac{\frac{G y}{M}}{\sum \frac{G_{f} y_{\mathrm{f}}}{M_{\mathrm{f}}}} P_{\text {general }} \\
& \frac{d t_{\text {mice }}}{d \tau}=\left(G_{\text {mice }} c_{\text {mice }} t_{\text {mice }}-G_{\text {mice }} \frac{x_{\text {micedi }}}{x_{\text {mice } f}} c_{\text {mice }} t_{\text {mice }}-G_{\text {pet }} i_{\text {pet }}+\alpha F\left(t_{\text {steam }}-t_{\text {miec }}\right)\right) / V_{L} p_{L} c_{L}
\end{aligned}
$$

\section{RESULTS AND DISCUSSION}

Aggregating mathematical models of processes in subsystems formalized computer model for the process of distillation of the miccella in the working area of the distiller of the miccella using the program "Matlab Simulink".

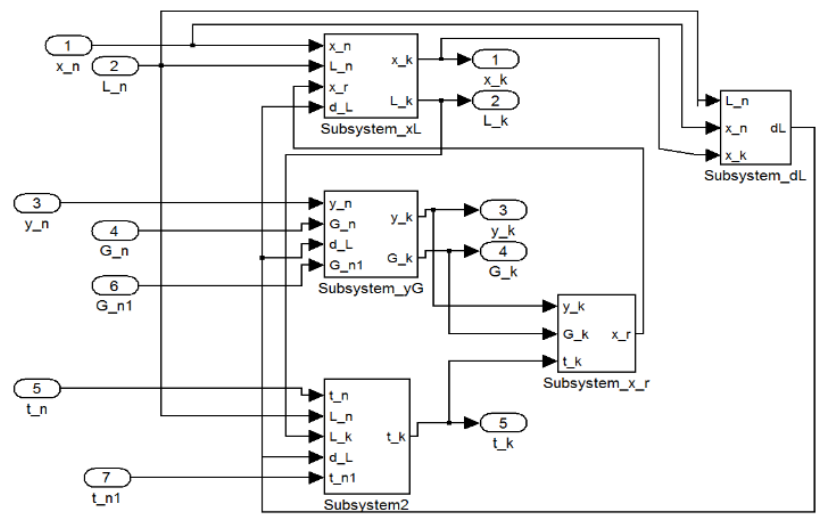

Fig.5. Computer model of the process of distillation of the miccella work area. 
Mathematical expressions of the working area of the device. A computer model of the final distillation unit composed of three working areas.
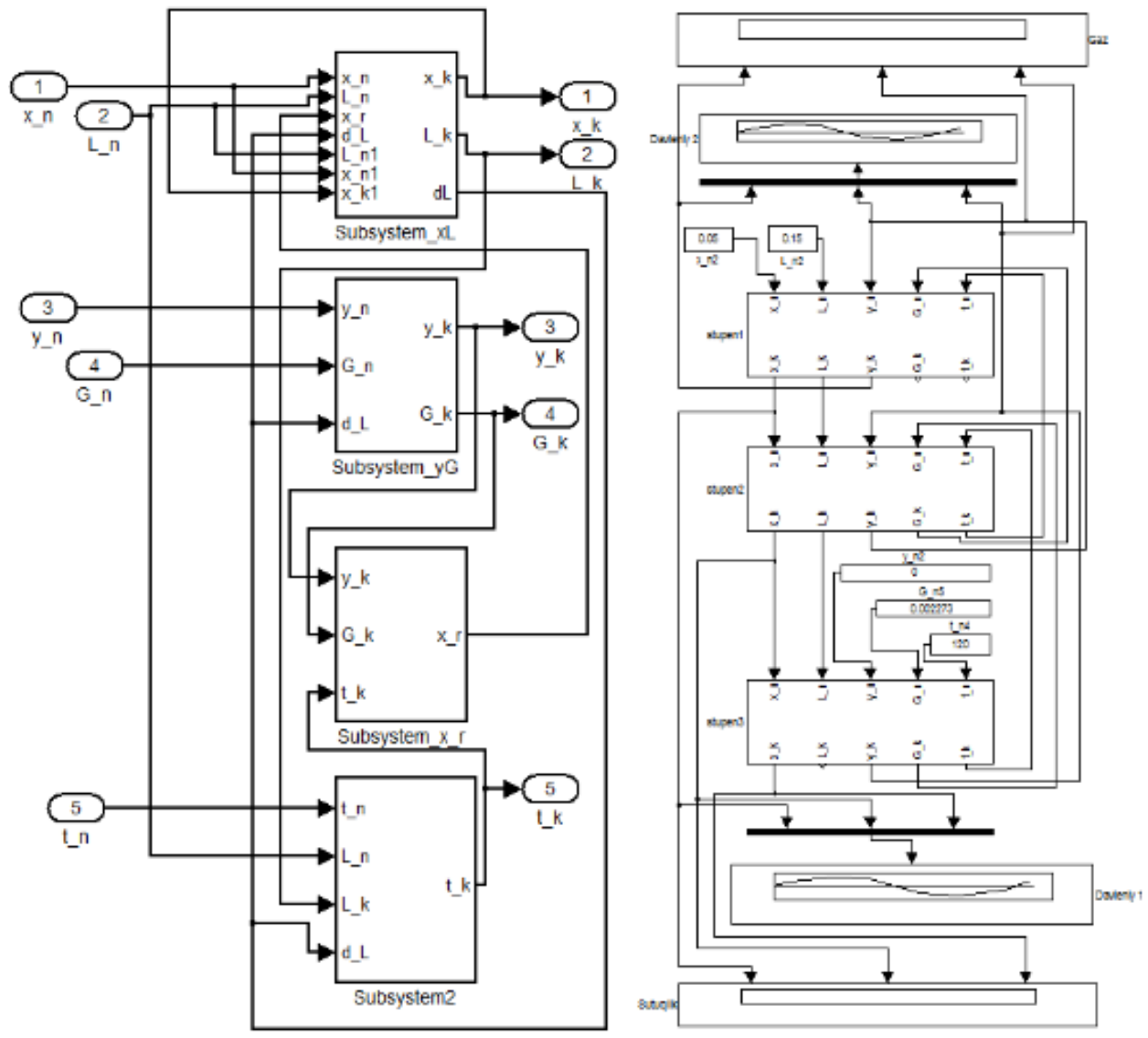

Fig.6. A computer model of the distillation process.

Each working area of the distiller has input and output parameters.

The output parameters of the first zone are the input parameters of the second zone. So, the output parameters of the previous stage are considered to be the input parameter of the next stage.

With the help of computer simulation in the program "Matlab Simulink" the model of the final distiller with the proposed new design of the device is constructed.

The calculation of the algorithm for calculating these parameters in the computer model is shown in the figure below. 

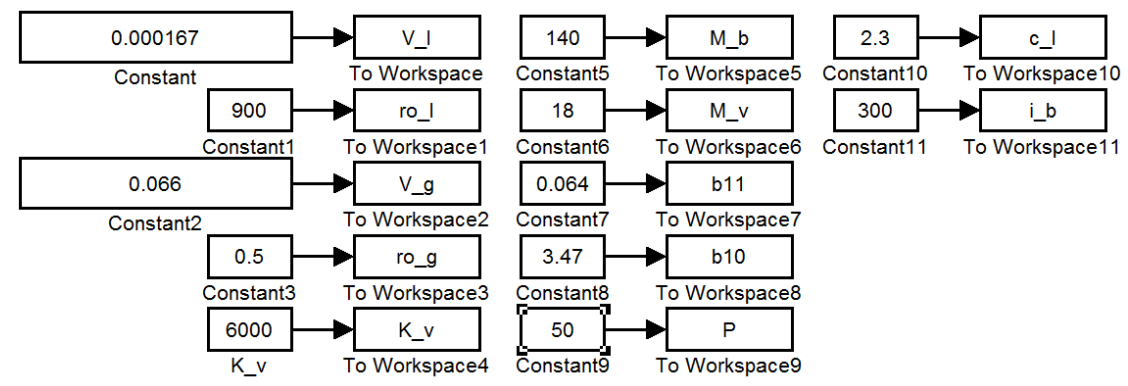

Fig.7. An algorithm for entering parameter values to perform calculations on a computer model.

The study of the mathematical model is performed at the following variation of the initial data.

Initial flow rate of the miccella, $0.15-0.17 \mathrm{~kg} / \mathrm{s}$

The initial concentration of the miccella in shares, $0.90-0.95$.

The initial temperature of the miccella, $100-150^{\circ} \mathrm{C}$.

The pressure in the distiller, 4-6 MPa.

Consumption of sharp water vapor, $0.015-0.03 \mathrm{~kg} / \mathrm{s}$.

As a result of the study of the computer model of the final distillation process of the cotton oil miccella, the following dependencies were obtained, which are shown in the graphs. 


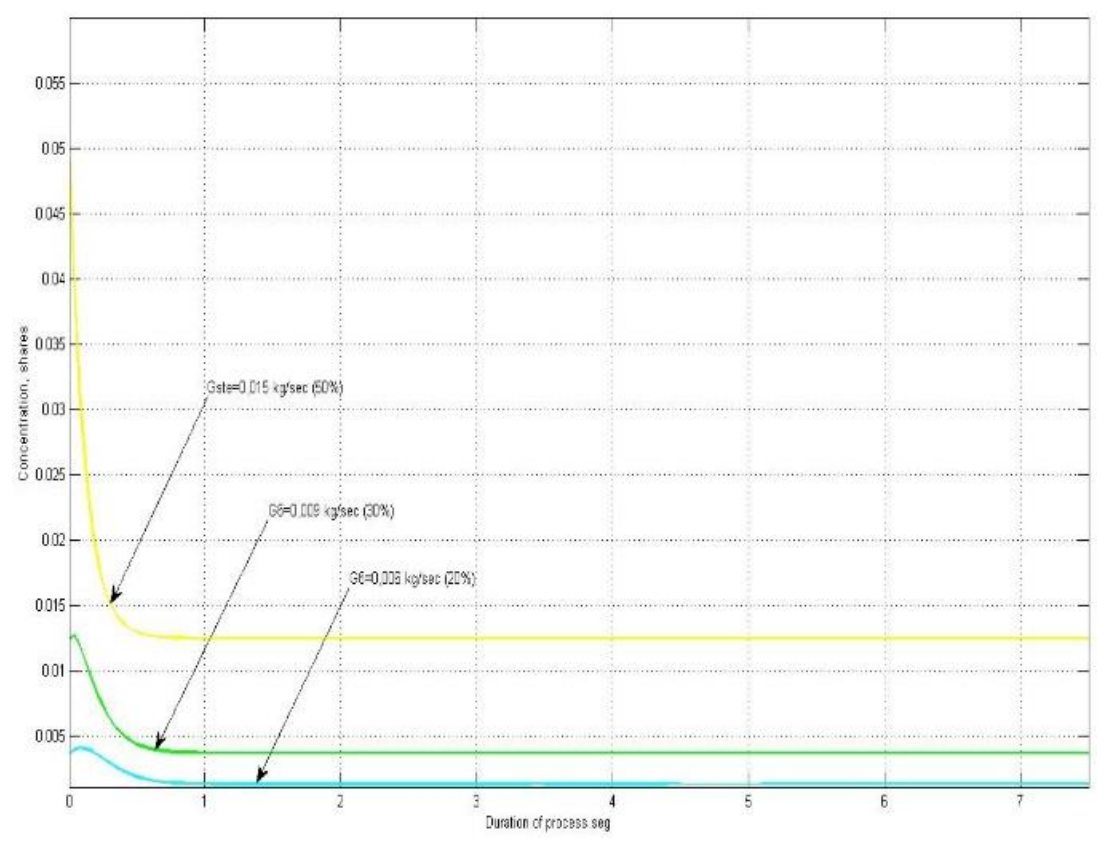

Fig.8. The change in the concentration of volatile component (extraction gasoline) in the liquid phase, depending on the time with the following parameters of the process.

$$
x_{n}=0,05 \%, t_{n}=130{ }^{\circ} \mathrm{C}, L_{n}=0,18, P_{u m}=50 \mathrm{KПа}
$$

When steam flow $\mathrm{G}_{\text {steam }}=0.015 \mathrm{~kg} / \mathrm{sec}$, the process temperature $t_{\text {initial }}=130^{\circ} \mathrm{C}$, the pressure in the apparatus $\mathrm{P}_{\text {general }}=50 \mathrm{kPa}$, the initial concentration $\mathrm{x}_{\text {initial }}=0,05$ a share, a concentration of volatile component in the liquid phase within seven seconds in the first zone of the device decreases to a share of 0.0125 .

Since the concentration is carried out in the apparatus of three consecutive zones, in the second zone the steam flow rate is $\mathrm{G}_{\text {steam }}=0.009$ $\mathrm{kg} / \mathrm{sec}$, the temperature $t_{\text {initial }}=130^{\circ} \mathrm{C}$, the calculated value of the final concentration of the volatile component in the liquid phase will be equal to the initial concentration $q_{\text {initial }}=0.0125$ fractions, for the second stage, the concentration of the volatile component in the liquid phase for eight seconds is reduced to 0.0035 fractions.

In the third zone of the apparatus, the steam consumption $\mathrm{G}_{\text {steam }}=0,006 \mathrm{~kg} / \mathrm{h}$, temperature $t_{\text {initial }}=130^{\circ} \mathrm{C}$, the initial concentration $x_{\text {initial }}=0,0035$ shares, the concentration of the volatile component in the liquid phase for ten seconds reduced to 0,0015 shares. 


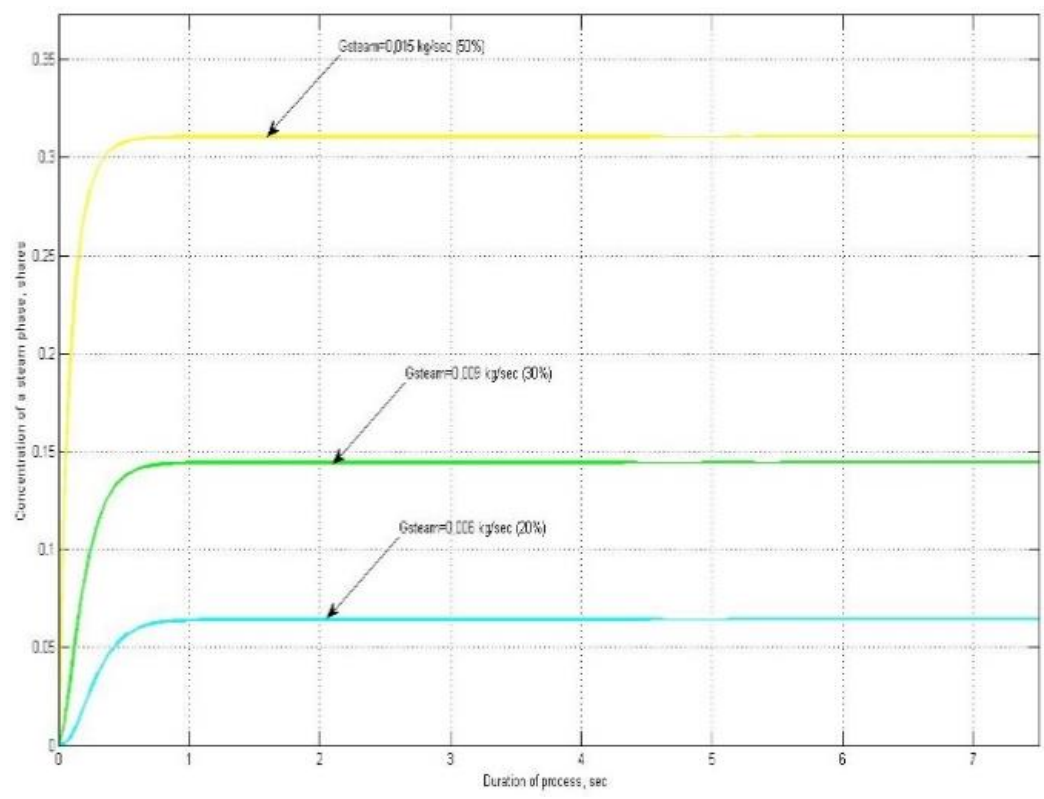

Fig.9. The change in the concentration of volatile component (extraction gasoline) in the liquid phase, depending on the time with the following parameters of the process. Steam $=0.05$ $\%, t_{\text {steam }}=130^{\circ} \mathrm{C}$, Steam $=0.18, P_{\text {general }}=50 \mathrm{kPa}$

\section{CONCLUSION}

At steam consumption Gsteam $=0,015 \mathrm{~kg} / \mathrm{sec}$, process temperature tinitial $=1300 \mathrm{C}$, the pressure in the apparatus Pgeneral $=50 \mathrm{kPa}$, the concentration of volatile component in the vapor phase for seven seconds in the first zone of the apparatus increases to 0.31 fractions.

Since the concentration is carried out in the apparatus of three zones connected in series, in the second zone the steam consumption is Gsteam=0.009 kg/sec, the temperature tinitial $=1300 \mathrm{C}$, while the concentration of the volatile component in the vapor phase for eight seconds increases to 0.14 fractions.

In the third zone of the apparatus, steam consumption Gsteam $=0,006 \mathrm{~kg} / \mathrm{sec}$, temperature tinitial $=1300 \mathrm{C}$, the concentration of volatile component in the vapor phase for ten seconds increases to 0.07 fractions.

\section{REFERENCES}

1. M. S. Narziev, O. R. Abdurakhmanov, F. Y. Khabibov, Karimova, D. sh. Investigation of flow hydrodynamic structures in the final distillation of a cotton miccella. "Problems and prospects of development of innovative cooperation in research and training." Bukhara. 2017.- Pp. 52-53

2. Zhang Hui, Li Xingang, Gao Xin. A method for modeling a catalyticdistillationprocess based on seepage catalytic packing 
internal.Chemical engineering science.

2013.-P.699-711.

3. Jain Deepak, Lau Yuk Man, KuipersA. M.,Discrete bubble modeling for a microstructured bubble column. 11th International Conference on Gas-Liquid and Gas-Liquid-Solid Reactor Engineering (GLS) Held in Conjunction with 9th World Congress on Chemical Engineering (WCCE)/Asian Pacific Conference on Chemical Engineering (APCChE) Seoul, South Korea. 2013.- P.19-22.

4. Babaev T. D. Improvement of technological process of distillation of cotton miccella and development of equipment for its implementation: abstract. Dissertation of candidate of technical Sciences. L.; VNIIG, 1992. $-64 \mathrm{p}$.

5. Computer - aided methods of analysis and synthesis of chemical engineering systems: textbook for undergraduates of technological specialties/ Ministry of higher and secondary special education of the Republic of Uzbekistan - T.:"Voris nashriyot". 2012/c -160.

6. Brinkmann Ulf, Janzen Anna,KenigEugeny Y.Hydrodynamicanalogy approach for modelling reactive absorption.Chemicalengineeringjournal. 2014.- P.342-353. 